\title{
Age of Drinking Onset and Unintentional Injury Involvement After Drinking
}


This publication is distributed by the U.S. Department of Transportation, National Highway Traffic Safety Administration, in the interest of information exchange. The opinions, findings and conclusions expressed in this publication are those of the author(s) and not necessarily those of the Department of Transportation or the National Highway Traffic Safety Administration. The United States Government assumes no liability for its content or use thereof. If trade or manufacturer's names or products are mentioned, it is because they are considered essential to the object of the publication and should not be construed as an endorsement. The United States Government does not endorse products or manufacturers. 


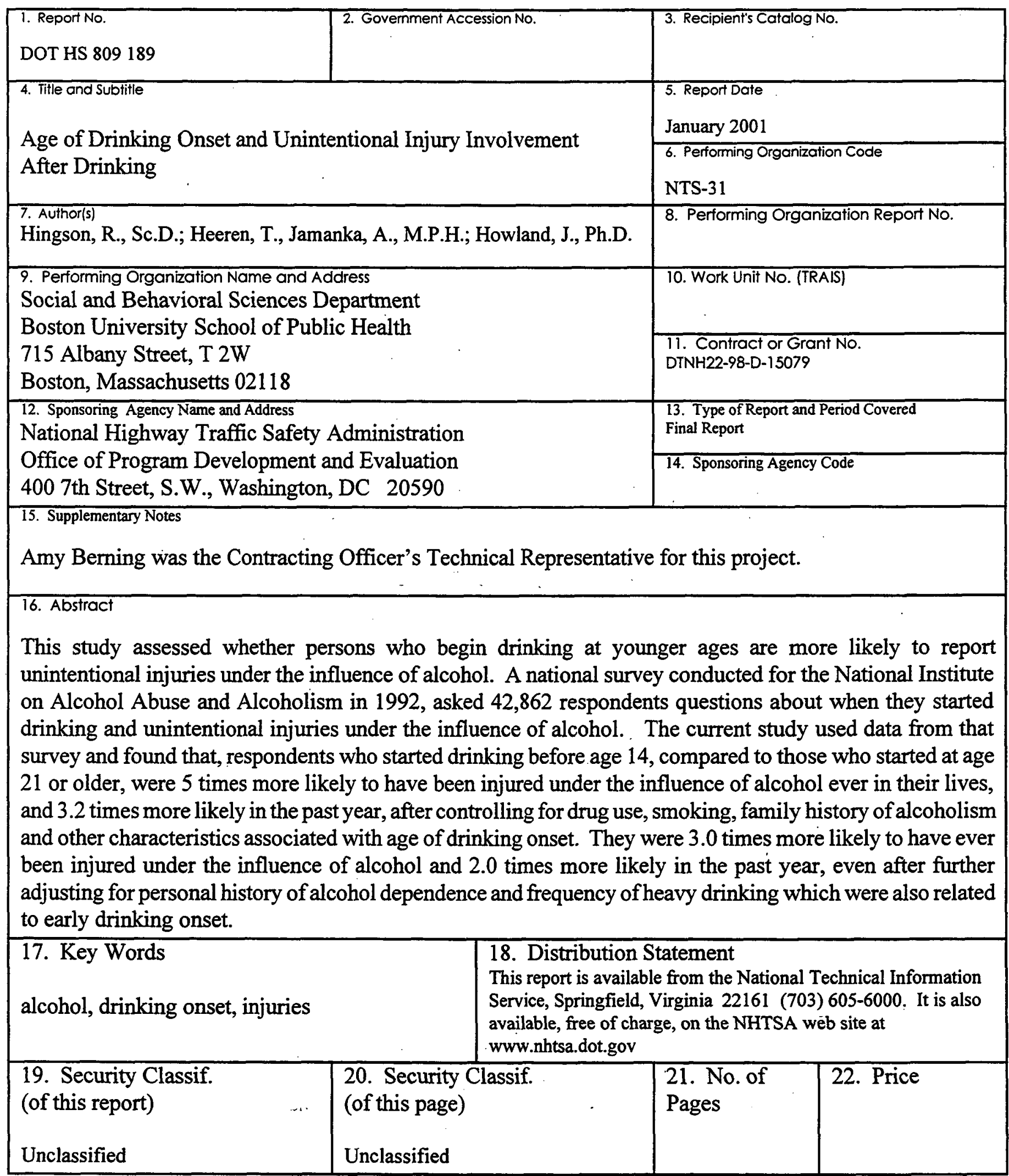




\section{ACKNOWLEDGEMENT}

The National Longitudinal Alcohol Epidemiology Study (NLAES) was sponsored by the National Institute on Alcohol Abuse and Alcoholism (NIAAA). Dr. Bridget Grant is the principal investigator of the NLAES project and provided us with the database. She is Chief of the Biometry Branch in the Division of Biometry and Epidemiology at NIAAA. 


\section{INTRODUCTION}

In $1997,92,253$ people died from unintentional injuries, the leading cause of death from age 1-44. ${ }^{1}$ In 1997, 42,013 of the unintentional injury deaths resulted from motor vehicle crashes ${ }^{2}$ and the balance from other unintentional injuries such as falls, drownings, burns, and unintended gun shot wounds.

Alcohol is a major contributor to traffic crashes. Thirty-eight percent of traffic deaths involve alcohol and each year at least 300,000 persons are injured annually in police- reported alcohol-related traffic crashes. ${ }^{3}$ Even at blood alcohol concentrations (BACs) as low as .02, alcohol affects driver performance by slowing reaction time and the decision making process. ${ }^{4}$ Epidemiologic research comparing BACs of drivers in single vehicle fatal crashes with those of drivers stopped at random in nationwide surveys indicates that each .02 increase in BAC nearly doubles a driver's fatal crash risk, and more than doubles the risk for male drivers age $16-20 .^{5}$ The risk increases more rapidly with each drink among drivers under age $21 .^{5.6}$

Alcohol use is also associated with non-traffic unintended injuries. A case control study assessing the risk of falls when drinking revealed a 10 -fold increased risk of death at BACs between .10 and .15 percent and a 60 -fold increased risk at BACs above .16. Nationwide analyses of 331 Medical Examiner studies of 7,459 unintentional non-traffic injury deaths, over 80 percent of whom were tested for alcohol, revealed that 31 percent of unintentional injury deaths had BACs of .10 or higher. ${ }^{8}$

To reduce alcohol-related fatal crashes among youth, all states have adopted a minimum legal drinking age (MLDA) of 21. States adopting MLDAs of 21 in the early 1980s experienced a 10-15 percent decline in alcohol-related traffic deaths among drivers in the targeted ages compared with states that did not adopt such laws. ${ }^{9}$ The National Highway Traffic Safety Administration (NHTSA) has estimated that the MLDA of 21 prevents 700-1,000 traffic deaths annually among persons under 21 , and over 18,000 traffic deaths among persons under 21 have been prevented since $1975 .^{3}$ Benefits of raising the drinking age may extend beyond reductions in traffic crashes. Jones and colleagues $(1992)^{10}$ reported lower rates of death caused by suicide and unintentional non traffic injuries among persons under 21 in states with higher MLDAs.

MLDA laws not only decreased drinking among persons under 21 , they also lowered drinking among people age 21-25 who grew up in states with MLDAs of 21 relative to those who grew up in other states." However, it is not known whether these laws and other efforts to prevent underage drinking reduce drinking and unintentional injury involvement later in life.

A recent analysis of the National Longitudinal Alcohol Epidemiology Survey (NLAES) ${ }^{12}$ found that age of drinking onset was strongly related to having experienced alcohol dependence during one's life as defined by Diagnostic and Statistical Manual, Fourth Edition (DSM-IV) ${ }^{13}$, a finding previously reported in smaller studies ${ }^{14}$ and those using Diagnostic Interview Schedule of the Diagnostic and Statistical Manual, American 
Psychiatric Association (DIS DSMIII) criteria. ${ }^{15}$ Among both males and females, and persons with and without a family history of alcoholism, persons who began drinking regularly before age 14 were at least 3 times more likely than those who did not drink until they were over age 21 to experience diagnosable alcohol dependence during their life. Questions in that survey permit us to explore whether early age of drinking onset was related to respondents drinking heavily, placing themselves in situations that increased their risk of injury, and having experienced an unintentional injury after drinking, even after controlling for alcohol dependence and other personal characteristics associated with the age respondents started drinking.

\section{METHODS}

The National Longitudinal Alcohol Epidemiologic Survey (NLAES) was a National probability survey sponsored by the National Institute on Alcohol Abuse and Alcoholism (NIAAA). In 1992, the U.S. Bureau of the Census administered for NIAAA face to face interviews with 42,862 respondents age 18 and older, mean age 44 , residing in the non-institutionalized population of the contiguous states including the District of Columbia.

\section{Sample Design:}

The multi-stage sampling approach used for NLAES was described by Massey et. al., $1989^{16}$. Primary sampling units (PSUs) were stratified according to socioeconomic criteria and were selected with a probability proportional to their population size. Within PSUs, geographically defined secondary sampling units, referred to as segments, were selected systematically for the sample. The African American population was oversampled at this stage of the sample selection to secure adequate numbers for analytic purposes. Segments were then divided into clusters of 4-8 housing units, and all occupied housing units were included in the survey. Within each household, one randomly selected person age 18 and older was selected to participate. Young adults age 18-29 were oversampled at a ratio of 2.25:1.00 at this stage of sample selection to include a greater representation of this heavier drinking population subgroup. Weighting using the Survey Data Analysis Statistical Package (SUDAAN) ${ }^{17}$ adjusted for the deliberate oversampling of African Americans and persons age 18-29 and accounted for the complex sampling design of NLAES. The household response rate for this representative sample of the U.S. population was 91.9 percent and the sample person response rate was 97.4 percent. The overall response rate was 90 percent.

Alcohol use and alcohol dependence assessment:

Measures of alcohol use and dependence were derived from the Alcohol Use Disorder and Associated Disabilities Interview Schedule (AUDADIS) ${ }^{18}$; a fully structured diagnostic psychiatric interview designed to be administered by trained interviewers who were not clinicians.

The age of drinking onset was ascertained by asking respondents how old they were when they first started drinking, not counting small tastes or sips of alcohol. Drinking onset data was collected from respondents who were classified as current drinkers (persons who had consumed at least 12 drinks in the past 12 months) and former 
drinkers (persons who had consumed at least 12 drinks in any one year of their lives but not during the year prior to the interview). Only current and former drinkers were included in the analysis. In an independent test retest study before the full NLAES was conducted, the test retest reliability of the drinking onset variable was good with a Kappa of $0.72^{19}$.

The definition of lifetime alcohol dependence was based on the diagnostic criteria of the Diagnostic and Statistical Manual, Fourth Edition (DSM-IV). The AUDADIS interview included an extensive list of symptom questions that operationalize the DSMIV criteria for alcohol dependence. Diagnosis of alcohol dependence required that in any one year a respondent meet at least three of the following seven criteria for dependence: 1) tolerance, 2) withdrawal or avoidance of withdrawal, 3) persistent desire or unsuccessful attempts to cut down or stop drinking, 4) spending much time drinking, obtaining alcohol, or recovering from its effects, 5) giving up or reducing occupational, social, or recreational activities in favor of drinking, 6) impaired control over drinking and 7) continuing to drink despite a physical or psychological problem caused or exacerbated by drinking. In the analysis, respondents were classified as either showing a alcohol dependence diagnosis in the past year, or at any time prior to the past year or never. The independent test retest study determined good reliabilities with Kappas of 0.76 , and $\mathbf{0 . 7 3}$ for past year and prior to past year dependence diagnoses respectively ${ }^{19}$.

Family history of alcoholism was ascertained through a series of questions that asked about different types of first degree biologic relatives (i.e., parents, children and siblings). The respondent was asked how many of each type of relative lived to be at least 10 years old and how many were ever alcoholics or problem drinkers. An alcoholic or problem drinker was defined for the respondents in a manner consistent with DSM-IV criteria for alcohol use disorder

"By an alcoholic or problem drinker, I mean a person who has a physical or emotional problem because of drinking, problems with a spouse, family or friends because of drinking; problems at work because of drinking, problems with police because of drinking- like drunk driving-or a person who seems to spend a lot of time drinking or being hung over."

In a test retest study conducted in conjunction with the NLAES, the family history items showed good to excellent reliability with Kappas at 0.72 for fathers, 1.00 for mothers, 0.90 for brothers, 0.73 for sisters and 0.65 each for sons and daughters ${ }^{19}$. In this study a respondent was classified as Family History Positive (FHP) if any of their first-degree relatives were reported as having been an alcoholic or a problem drinker.

Current heavy drinking was determined by asking respondents, "During the past 12 months, about how often did you have five or more drinks of any type of alcohol in a single day?" Respondents were also asked, "About how often would you say you usually drank enough to feel drunk during the last 12 months? By drunk, I mean times when your speech was slurred, you felt unsteady on your feet or you had blurred vision." 
We also constructed a measure of the frequency with which respondents drank five or more drinks during their period of heaviest drinking in their life. Respondents were asked whether there were periods in their life when they drank more than in the past year. Respondents who answered yes were then asked their frequency of drinking and the amounts they usually consumed on days they drank during this period. They were also asked what was the greatest amount they drank on any day during that period and how frequently they drank that amount. We used data from these questions as well as questions about frequency of drinking five or more drinks in the past year to determine their frequency of drinking five or more drinks during their lifetime period of heaviest drinking.

Taking risks that might lead to injury was assessed by a question, "In your life, did you ever get into a situation while drinking or after drinking that increased your chances of getting hurt - like swimming, using machinery, or walking in a dangerous area or around heavy traffic? Did that happen in the past 12 months?" Finally, life time and past year alcohol related injury involvement were explored by asking respondents "In your entire life, did you ever accidentally injure yourself under the influence of alcohol, for example have a bad fall, or cut yourself badly, get hurt in a traffic accident, or anything like that? Did this happen in the past 12 months?"

\section{Statistical Analysis:}

All statistical analyses were conducted using the SUDAAN statistical package to account for the survey design ${ }^{17}$. Age of drinking onset was categorized as under 14, each year separately from 14 through 20 , and 21 or older and all analyses focused only on respondents who responded to this question. The significance of relations between age of drinking onset and respondent background characteristics was tested using chi square analysis.

We examined the relation between age of drinking onset and frequency of heavy drinking, adjusting for background characteristics including history of alcohol dependence through a series of multiple logistic regression analyses. We examined the following outcomes as dichotomous variables, whether or not respondents:

-drank at least $5+$ drinks at least once per week in the past year;

-drank to intoxication at least weekly in the past year;

-drank 5+ drinks at least daily during the period when respondents drank most heavily.

Odds ratios and $95 \%$ confidence intervals were calculated describing the increased risk of these outcomes for those with drinking onset before age 14 and at each age from 14 through 20 relative to those who started drinking after age 21 .

To assess whether age of drinking onset was related to injury outcomes, we also conducted multiple logistic regression analyses examining as dichotomous outcome variables, whether or not respondents ever or in the past year: 
- got into a situation while or after drinking that increased their risk of injury

- accidentally injured themselves under the influence of alcohol.

The regressions were conducted twice. First, we entered the personal social and demographic characteristics associated with age of drinking onset other than alcohol dependence and measures of heavy drinking frequency; then we added measures of alcohol dependence and heavy drinking. This was done to assess whether any relations between age of drinking onset and injury involvement were primarily a function of those who started drinking earlier in life being more likely to experience more frequent heavy drinking episodes.

We entered the frequency of heavy drinking during the respondent's heaviest drinking period into the regressions examining life time exposure to injury risks and injury involvement, and the past year frequency of heavy drinking measures into the regressions examining past year exposure to injury risk and injury involvement.

For consistency across models, the entire set of background variables was included in the analysis of each drinking and injury outcome.

\section{RESULTS}

Sixty-six percent of respondents $(\mathrm{N}=27,081)$ ever drank alcohol, 49 percent before age 21 and 3 percent before age 14. The mean drinking onset age was 19 years. Thirteen percent of the sample $(\mathrm{N}=5368)$ were diagnosed as being alcohol dependent ever in their life and 4 percent in the past year $(\mathrm{N}=1713)$. Twenty-five percent reported a family history of alcoholism $(\mathrm{N}=10481)$. In the past year five percent $(\mathrm{N}=2,082)$ of respondents reported drinking 5+ drinks in a single day at least once per week and 1 percent $(N=635)$ reported drinking enough to get drunk at least once per week. During their period of heaviest drinking, seventeen percent $(\mathrm{N}=7198)$ reported consuming five plus drinks on an occasion at least weekly and four percent $(\mathrm{N}=1608)$ did so everyday.

Fifteen percent $(\mathrm{N}=3,933)$ of those who ever drank reported having been in a situation after drinking that increased their chance of injury ever in their lifetime, and 3 percent $(\mathrm{N}=776)$ in the past year. Eight percent of those who ever drank $(\mathrm{N}=2150)$ reported accidentally injuring themselves under the influence of alcohol ever in their life and two percent $(\mathrm{N}=378)$ in the past year.

Respondents who began drinking at younger ages were much more likely than those who did not start drinking until they were 21 or older to report heavy drinking both in the year prior to the survey and during their period of heaviest drinking. Those whose drinking began prior to age 14 were more than 3 times more likely to report consuming 5 or more drinks on a single day at least once per week during the past year, 16 percent vs. 5 percent. They were 7 times more likely to report drinking enough to be intoxicated at least once per week, 7 percent vs. 1 percent (Figure 1). Further, they were five times more likely to report drinking $5+$ daily during their period of heaviest drinking 26 percent vs 5 percent. 
Early age of drinking onset was also strongly related to both being in situations while or after drinking that increased a person's chances of being injured and being accidentally injured under the influence of alcohol. Compared to respondents who began drinking at age 21 or older, those who began drinking prior to age 14 were nearly 7 times more likely to report having been in situations that increased their chance of injury, ever in their life $34 \%$ vs. $5 \%$ and in the past year $7 \%$ vs $1 \%$ (Figure 2). Further, persons drinking prior to age 14 were 12 times more likely to have ever been accidentally injured under the influence of alcohol ever in their life $24 \%$ vs. $2 \%$, and at least 10 times more likely to have been injured this way in the past year, $5 \%$ vs. $0.4 \%$ (Figure 3 ).

Relationships between age of drinking onset and measures of frequency of heavy drinking as well as exposure to situations posing risk of injury and injury involvement were monotonic from drinking onset at age 14 to age 21 and older. The younger respondents were when they began drinking, the greater the frequency of heavy drinking and experiencing injuries after drinking.

Frequent heavy drinking in the past year and during the period when respondents drank most was associated with greater risk of injury involving alcohol. To illustrate, 29 percent who drank to intoxication at least weekly in the past year were in a situation that year after drinking that posed a risk for injury $(\mathrm{N}=186 / 635)$ compared to 3 percent of drinkers who never drank to intoxication in the past year $(\mathrm{N}=63 / 19008)(\mathrm{p}<.001)$. Seventeen percent who drank to intoxication at least once per week in the past year were injured under the influence of alcohol in the past year $(\mathrm{N}=110 / 635)$ compared to 0.1 percent of lifetime drinkers who never drank to intoxication in the past year $(\mathrm{N}=14 / 19008)(\mathrm{p}<.001)$. In addition, several subgroups in the study were significantly more likely to have begun drinking at earlier ages: male respondents, younger respondents, those with less than a high school education, persons never married, persons who currently or ever smoked or used illicit drugs, persons who were currently or ever alcohol dependent and respondents reporting a family history of alcoholism (all relations $\mathrm{p}<.001$; data available upon request).

The regressions examining the relation between age of drinking onset and drinking behavior are presented in Table 1 . They revealed that after controlling for diagnoses of alcohol dependence and other variables related to age of drinking onset, the younger respondents were when they started drinking, the more likely they were in the past year to drink 5+ on an occasion and to drink to intoxication at least once per week. Compared to those who began drinking at age 21 or older, those who began before age 14 were nearly 1.4 times more likely to drink $5+$ drinks and 2.8 times more likely to drink to intoxication at least weekly in the past year. They were also 3.1 times more likely to consume 5+ drinks daily during their lifetime period of heaviest drinking.

Tables 2-3 present results of regression analyses examining the relation between age of drinking onset and injury outcomes. The regression analyses on injury outcomes (not including alcohol dependence and drinking measures) revealed that even after controlling for other personal characteristics associated with age of drinking onset, respondents who began drinking before age 14 relative to those who started at age 21 or 
older were 5.0 times more likely to have ever been in a situation after drinking that increased their risk of injury and 3.2 times more likely to have done so in the past year (Table 2, Models 1a, b). They were also 4.8 times more likely to have ever been injured under the influence of alcohol and 2.4 times more likely to have been injured this way in the past year (Table 3, Models 1a,b). Even when we included in the regressions, measures of alcohol dependence, frequency of drinking 5+ during a respondent's period of heaviest drinking and past year frequency of drinking $5+$ or to intoxication (each of which were independently related to our study outcomes), those who began drinking prior to age 14 relative to those who started at age 21 or later were 3.0 times more likely ever and 1.5 times more likely in the past year to have been in a situation after drinking that increased their risk of injury (Table 2, Models 2a,b). They were also 3.0 times more likely ever and 2.0 times more likely in the past year to have been injured under the influence of alcohol (Table 3, Models $2 \mathrm{a}, \mathrm{b}$ ).

Further, lifetime elevated injury risks were not confined only to those who began drinking before age 14. Persons who began drinking in each age group under 21 relative to those who started when they were 21 and older were significantly more likely during their lives to have ever been injured under the influence of alcohol and to have placed themselves in situations after drinking that increased their risk of injury. This was found even after controlling for history of alcohol dependence, frequency of heavy drinking during respondents heaviest drinking period and numerous other characteristics related to age of drinking onset (Tables 2-3, Model 2a).

Our analyses also indicated that a large part of the relation between early age of drinking onset and unintentional injury under the influence of alcohol in the past year resulted from those who began drinking at an early age reporting more frequent heavy drinking in the past year. Persons who began drinking in each age group 17 and younger were significantly more likely than those starting at age 21 and older to have been injured after drinking in the past year when we controlled for the initial set of characteristics related to age of drinking onset (Table 3, Model 1b). However, after further analytically adjusting for diagnosis of alcohol dependence and for frequency of drinking 5+ on an occasion or to intoxication in the past year, only those who began drinking before age 14 were significantly (2.0 times) more likely to have been injured in the past year under the influence of alcohol (Table 3, Model 2b). Diagnosis of current alcohol dependence and frequency of heavy drinking accounted for the significant relation of early drinking age onset to injury after drinking in the past year. Frequent heavy drinking in the past year, which is more common among those who started drinking early in life, is particularly problematic given the disproportionate willingness of people who began drinking early in life to place themselves in situations after drinking that increase their risk of injury (Table 2). Even after controlling for measures of current alcohol dependence, and past year frequency of drinking $5+$ or to intoxication, persons who began drinking prior to age 18 were also significantly more likely than those starting at age 21 or older to place themselves in situations after drinking in the past year that increased their risk of injury (Table 2, Model 2b). 


\section{DISCUSSION}

Previous studies have indicated that the younger the age people in the United States are when they begin drinking, the greater the likelihood they will experience alcohol dependence during their life time ${ }^{12,13}$. Analyses presented in this report indicate that even after analytically controlling for personal history of alcohol dependence and other respondent characteristics related to age of drinking onset, the younger people are when they start drinking, the more frequently they report drinking 5+ drinks or to intoxication. For example, compared to persons who started drinking at age 21, those who started at age 14 were 2.8 times more likely to drink to intoxication on at least one day each week in the past year.

Previous research has also shown that raising the drinking age to 21 reduces alcohol-related traffic deaths and other unintentional injury deaths among persons under age $21^{9,10}$. This report raises the possibility that efforts to delay drinking onset may be associated with reductions in traffic and other unintentional injuries under the influence not only among persons under the age of 21 , but also among those above the legal drinking age. After controlling for respondent characteristics related to age of drinking onset including measures of current and life time alcohol dependence and the frequency respondents drank 5+ drinks during their period of heaviest drinking, persons who started drinking in each age group under 21 relative to those starting at age 21 and older were significantly more likely to have placed themselves in situations after drinking that increased their risk of injury. They were also significantly more likely to have been accidentally injured during their lifetime under the influence of alcohol.

The relationship between early age of drinking onset and injury involvement under the influence was found not only over the course of the respondent's life but in the year prior to the survey as well. However, our analyses indicate that a large part of the relation between early onset of drinking and past year injury involvement results from those who started drinking at younger ages drinking heavily more frequently in the past year (regardless of whether they were alcohol dependent). Persons who started drinking prior to age 18 were also significantly more likely to place themselves in situations after drinking that increased their risk of injury even after controlling for past year alcohol dependence and frequency of heavy drinking.

We should caution that the results of this study were based on self-report in a cross sectional survey, where data are collected at one point in time from a sample selected to describe a larger population at that time (see Babbie E. Survey Research Methods) ${ }^{20}$ and hence may be subject to limitations associated with self-report. On the one hand, social desirability biases may lead to underreporting of alcohol use and injury involvement after drinking. On the other hand, persons willing to report heavy drinking may be less hesitant than others to report injury involvement after drinking. Although the sample was nationally representative, very large and the 90 percent response rate was excellent, it would be useful to replicate these results in a longitudinal study with chemical markers in addition to self-report. 
Also, it should be noted that it is possible that people who engage in a variety of deviant or illegal behaviors at an early age are more likely to continue them later in life. However, the relationships between early drinking onset and recent heavy drinking and injury involvement were independent of the current or past use of illegal drugs or tobacco.

Our findings point to a need for additional research in two areas. First there is a need for research that explains why starting to drink at an early age relates alcohol dependence to heavier drinking later in life even among persons who are not dependent. Genetics may play a role by predisposing certain individuals to exhibit tolerance to physiologic effects of alcohol early in their drinking careers thereby contributing to the establishment of heavier drinking patterns later in life. ${ }^{21}$ Familial sources including both shared genetic and environmental may account for the early onset later dependence relation. ${ }^{22}$ Persons who drink earlier may have physiologic changes that contribute to greater tolerance and the need to drink more to achieve the same pleasurable sensations after drinking. Persons who start drinking earlier in life may learn to drink in less controlled situations with peers whose drinking norms are to drink to intoxication rather than with family and parents whose norms might tend more towards moderate drinking.

Second, there is also a need for research examining why even when diagnosis of alcohol dependence and measures of frequency of lifetime and past year heavy drinking are controlled, persons who began drinking at an earlier age are more likely to place themselves in situations that pose risk of injury. Several explanations are possible. Those who begin drinking at an early age may be less fearful of injury and situations that pose risk of injury. Some may derive pleasure or a sense of self-esteem by taking risks associated with injury. It is well known that persons who drive after drinking, for example, are more likely to speed and are less likely to wear seat belts. ${ }^{23}$ Alternatively, persons who start drinking at earlier ages may not be as aware or appreciate how alcohol increases injury risk. Other studies have shown that people who drive after heavy drinking are more likely to believe they can drive safely after higher amounts of alcohol consumption. ${ }^{24}$ They may believe for example the risk of traffic crashes and other injuries increase only for people who are visibly intoxicated..

In sum, this study indicates that early onset of drinking increases frequent heavy drinking which in turn heightens risk of alcohol related injuries among persons under the legal drinking age of 21 and among adults over age 21 not only for persons with diagnosable alcohol dependence, but other drinkers as well. Further, those who begin drinking at an early age report more often placing themselves ever, and in the past year, in situations after drinking that increase risk of injury. That was found not only among alcohol dependents and others who more frequently drink heavily and to intoxication but other drinkers as well. Physicians and other health care providers should counsel their patients who start drinking at an early age not only about their increased risk for alcohol dependence, but also their increased risk of experiencing unintentional injury under the influence of alcohol. 
Recent national surveys indicate that after a decade of decline, the percentage of high school seniors who drink, drink heavily and drive after drinking has increased in the past two years. ${ }^{25}$ The study reported here identifies important new reasons to expand clinical, educational, legal and community interventions that delay onset of drinking. 


\section{REFERENCES}

1. U.S. Centers for Disease Control 2000.

2. National Highway Traffic Safety Administration. Traffic Safety Facts 1995. Washington, DC: U.S. Department of Transportation; 1996.

3. National Highway Traffic Safety Administration. Traffic Safety Facts: Alcohol 1997. Washington, DC: U.S. Department of Transportation; 1998.

4. Moskowitz $\mathrm{H}, \mathrm{A}$ review of the literature on the effects of low doses of alcohol on driving related skills. National Highway Traffic Safety administration 2000 DOT HS 809028.

5. Zador PL., Krawchuk S., and Voas R.B. Alcohol related relative risk of driver fatalities and driver involvement in fatal crashes in relation to driver age and gender. J. Studies on Alcohol. 2000; 61:387-395.

6. Mayhew DR, Simpson HM. Alcohol, age, and risk of road accident involvement. In: Raye A; Meyer GB eds. Alcohol Drugs and Traffic Safety,eds. San Juan, PR: Proceedings of the Ninth International Conference on Alcohol Drugs and Traffic Safety; 1983:937-947.

7. Honkanen R, Ertama L, Kuosmanen $P$, Linnoila M, Alha A, Visuri T. The role of alcohol in accidental falls. $J$ of Studies on Alcohol. 1983; 44:231-245.

8. Smith G, Branngs $C$, Miller T. Fatal non traffic injuries involving alcohol: a metaanalysis. Annals of Emergency Medicine 1999; 33: 699-702..

9. General Accounting Office. Drinking age laws: an evaluation synthesis of their impact on highway safety. Washington, DC: General Accounting Office; 1987.

10. Jones N, Pieper C, Robertson LS. The effect of legal drinking age on fatal injuries of adolescents and young adults. American Journal of Public Health. 1992; 82(1):112114.

11. O' Malley P, Wagenaar A. Effects of minimum drinking age laws on alcohol use, related behaviors, and traffic crash involvement among American youth. J. of Studies on Alcohol. 1991; 52:478-491.

12. Grant B. The impact of family history of alcoholism on the relationship between age at onset of alcohol use and DSM-III alcohol dependence. Alcohol Health and Research World. 1998; 22:144-147.

13. American Psychiatric Association Diagnostic and Statistical Manual of Mental Disorders (DSMIV), Washington, D.C., 1994. 
14. Clapper R. Bulca S., Goldfield Z, Lipsett L., Tsuang M., Adolescent problem behaviors as predictors of adult alcohol diagnoses. International Journal of the Addictions.1995;30(5):507-523.

15. American Psychiatric Association Diagnostic and Statistical Manual of Mental Disorders (DSM III), Washington, D.C., 1987.

16. Massey JT, Parsons VL, Tadros W. Design and estimation for the national health interview survey, 1985 - 1994. In: Vital and Health Statistics Report Series 2(10), Hyattsville, MD: U.S. Department of Health and Human Services, National Center for Health Statistics; 1989.

17. Shah BV, Barnwell BG, Bieler GS. SUDAAN User's Manual, Release 7.0. Research Triangle Park, NC: Research Triangle Institute; 1996.

18. Grant B.F., Hasin D.S.: The alcohol use disorders and associated disabilities interview schedule. National Institute on Alcohol Abuse and Alcoholism. Rockville, Maryland, 1992.

19. Grant B.F., Harford F.C., Dawson D.A., Chou P.S. and Pickering R.P. The alcohol use disorder and associated disabilities interview schedule: reliability of alcohol and drug modules in a general population sample. Drug and Alcohol Dependence 1995; 39: $37-44$.

20. Babbie E., Survey Research Methods, Wadsworth Publishing, Belmont California, 1990.

21. Shuckit M. New finding in the genetics of alcoholism. Journal of the American Medical Association 1999; 281(20):1875-1876.

22. Prescott C.A., Kendler K.S., Age at first drink and risk for alcoholism: a non causal association. Alcoholism Clinical and Experimental Research 1999; 23(1) 101-107

23. Hingson R., Howland J., Schiavone T., Damiata M., The Massachusetts saving lives program: six cities shift the focus from drunk driving to speeding, reckless driving and failure to wear safety belts. J. Traffic Medicine 1990: 123-132.

24. National Highway Traffic Safety Administration. National survey of drinking and drivers attitudes and behavior, Washington D.C.: U.S. Department of Transportation; DOT HS 808 438, 1996

25. O'Malley PM, Johnston LD. Drinking and driving among high school seniors. American Journal of Public Health1999; 89: 678-684. 


\section{Table 1}

\section{Adjusted Odds Ratios Frequency of Heavy Drinking Occasions According to Age Started Drinking}

Past Year Drank Heavily at least Once Per Week Lifetime Period of

Age of

Drinking Drank 5+ on an Occasion Drank to Intoxication Drank 5+ Daily

\begin{tabular}{c|ll|ll|ll|}
\cline { 2 - 7 } Onset & OR & $95 \% \mathrm{CI}$ & OR & $95 \% \mathrm{CI}$ & OR & $95 \% \mathrm{CI}$ \\
\cline { 2 - 7 }$<14$ & 1.44 & $1.1,1.88$ & 2.79 & $1.75,4.45$ & 2.76 & $2.13,3.58$ \\
14 & 1.70 & $1.2,2.42$ & 2.80 & $1.84,4.77$ & 2.37 & $1.65,3.40$ \\
15 & 1.56 & $1.19,2.03$ & 3.34 & $2.11,5.29$ & 2.12 & $1.61,2.79$ \\
16 & 1.34 & $1.07,1.69$ & 2.78 & $1.83,4.23$ & 1.52 & $1.21,1.91$ \\
17 & 1.25 & $0.99,1.58$ & 1.77 & $1.13,2.78$ & 1.29 & $1.00,1.67$ \\
18 & 1.26 & $1.02,1.55$ & 1.97 & $1.29,3.03$ & 1.27 & $1.03,1.57$ \\
19 & 1.33 & $1.02,1.72$ & 1.35 & $0.72,2.55$ & 1.21 & $0.91,1.62$ \\
20 & .96 & $0.7,1.31$ & 1.82 & $1.05,3.16$ & 1.07 & $0.79,1.45$ \\
$21+$ & 1.00 & - & 1.00 & - & 1.00 & - \\
\hline
\end{tabular}

Regressions control for Age, Gender, Race/Ethnicity (White Non Hispanic, Black Non Hispanic, Hispanic, Other), Education, Drug use (Current, Former, Never), Smoking (Current,Former, Never), Marital Status

(Never Married, Married, Other) Family History of Alcoholism, Alcohol Dependence (Current, Former, Never) 


\section{Table 2}

\section{Adjusted Odds Ratios of Being in a Situation After Drinking that Increased the Risk of Injury According to Age of Drinking Onset}

In a Situation After Drinking That Increased the Risk of Injury

\begin{tabular}{|c|c|c|c|c|c|c|c|c|}
\hline \multirow{3}{*}{$\begin{array}{l}\text { Age of } \\
\text { Drinking } \\
\text { Onset }\end{array}$} & \multicolumn{4}{|c|}{ Ever in One's Life } & \multicolumn{4}{|c|}{ In the Past Year } \\
\hline & \multicolumn{2}{|c|}{ Model 1a } & \multicolumn{2}{|c|}{ Model 2a } & \multicolumn{2}{|c|}{ Model 1b } & \multicolumn{2}{|c|}{ Model 2b } \\
\hline & OR & $95 \% \mathrm{CI}$ & OR & $95 \% \mathrm{CI}$ & OR & $95 \% \mathrm{CI}$ & OR & $95 \% \mathrm{CI}$ \\
\hline$<14$ & 4.82 & $3.96,5.89$ & 3.04 & $2.47,3.74$ & 2.38 & $1.52,3.71$ & 1.52 & $.95,2.43$ \\
\hline 14 & 5.23 & $4.20,6.32$ & 3.65 & $2.86,4.67$ & 2.85 & $1.81,4.47$ & 1.66 & $1.03,2.70$ \\
\hline 15 & 4.96 & $4.10,5.99$ & 3.32 & $2.72,4.06$ & 3.52 & $2.31,5.35$ & 1.97 & $1.27,3.04$ \\
\hline-16 & 3.29 & $2.80,3.88$ & 2.39 & $2.01,2.84$ & 2.64 & $1.76,3.94$ & 1.70 & $1.10,2.62$ \\
\hline 17 & 3.01 & $2.52,3.61$ & 2.34 & $1.94,2.82$ & 2.53 & $1.70,3.76$ & 1.69 & $1.11,2.56$ \\
\hline 18 & 2.05 & $1.76,2.39$ & 1.76 & $1.50,2.07$ & 1.40 & $0.97,2.01$ & 1.10 & $.74,1.67$ \\
\hline 19 & 1.94 & $1.56,2.43$ & 1.68 & $1.34,2.12$ & 1.71 & $1.06,2.78$ & 1.45 & $.88,2.38$ \\
\hline 20 & 1.44 & $1.15,1.80$ & 1.35 & $1.06,1.76$ & 1.53 & $0.90,2.61$ & 1.60 & $.91,2.83$ \\
\hline $21+$ & 1.00 & $-\tau$ & 1.00 & $\overline{-}$ & 1.00 & & 1.00 & - \\
\hline
\end{tabular}

Models 1a, 1b Control for Age, Gender, Race/Ethnicity (White Non Hispanic, Black Non Hispanic, Hispanic, Other), Education, Drug Use (Current, Former, Never), Smoking (Current, Former, Never), Marital Status (Married, Never Married, Other), Family Historyof Alcoholism

Models 2a, 2b Control for all variables in Model 1a, $1 b$ plus History of Alcohol Dependency (Current, Former, Never) frequency of drinking $5+$ on an occasion during the period when the respondent drank the most or past year frequency of drinking $5+$ on an occasion or drinkingo intoxication 


\section{Table 3}

\section{Adjusted Odds Ratios of Being Accidentally Injured Under the Influence of Alcohol According to Age of Drinking Onset}

Accidentally Injured Under the Influence of Alcohol

\begin{tabular}{|c|c|c|c|c|c|c|c|c|}
\hline \multirow{2}{*}{$\begin{array}{l}\text { Age of } \\
\text { Drinking } \\
\text { Onset }\end{array}$} & \multicolumn{2}{|c|}{$\begin{array}{l}\text { Ever in One's Life } \\
\text { Model 1a }\end{array}$} & \multicolumn{6}{|c|}{ In the Past Year } \\
\hline & OR & $95 \% \mathrm{CI}$ & $\mathrm{OR}$ & $95 \% \mathrm{CI}$ & OR & $95 \% \mathrm{CI}$ & OR & $95 \% \mathrm{CI}$ \\
\hline$<14$ & 4.99 & $3.91,6.36$ & 2.98 & $2.29,3.89$ & 3.19 & $1.77,5.78$ & 1.96 & $1.03,2.56$ \\
\hline 14 & 4.49 & $3.47,5.81$ & 2.96 & $2.26,3.88$ & 2.85 & $1.63,4.97$ & 1.46 & $0.84,2.53$ \\
\hline 15 & 4.69 & $3.79,5.85$ & 3.14 & $2.48,3.97$ & 2.98 & $1.75,5.08$ & 1.62 & $0.93,2.85$ \\
\hline 16 & 3.18 & $2.58,3.92$ & 2.38 & $1.90,2.98$ & 2.04 & $1.21,3.43$ & 1.24 & $0.73,2.13$ \\
\hline 17 & 2.67 & $2.12,3.36$ & 2.12 & $1.66,2.71$ & 2.15 & $1.29,3.58$ & 1.42 & $0.85,2.37$ \\
\hline 18 & 1.52 & $1.25,1.86$ & 1.33 & $1.08,1.64$ & 1.14 & $0.69,1.89$ & .83 & 0.56 .1 .37 \\
\hline 19 & 1.59 & $1.25,1.86$ & 1.42 & $1.07,1.89$ & 1.34 & $0.70,2.57$ & 1.10 & $0.58,2.07$ \\
\hline 20 & 1.41 & $1.04,1.91$ & 1.39 & $1.01,1.91$ & 1.14 & $0.57,2.28$ & 1.20 & $0.62,2.33$ \\
\hline $21+$ & 1.00 & - & 1.00 & -- & 1.00 & - & 1.00 & - \\
\hline
\end{tabular}

Models 1a, 1b Controls for Age, Gender, Race/Ethnicity (White Non Hispanic, Black Non Hispanic, Hispanic, Other), Education, Drug Use (Current, Former, Never), Smoking (Current, Former, Never), Marital Status (Married, Never Married, Other), Family History of Alcoholism, Personal History of Alcohol Dependence (Past Year, Former, Never) Models 2a, 2b Controls for all variables in Models $1 \mathrm{a}, \mathrm{lb}$ plus frequency of drinking $5+$ on an occasion during the period when the respondent drankthe most or past year
frequency of drinking $5+$ on an occasion or drinking to intoxication 


\section{Figure 1. Heavy Drinking at Least Once Per Week According to Age of Drinking Onset}

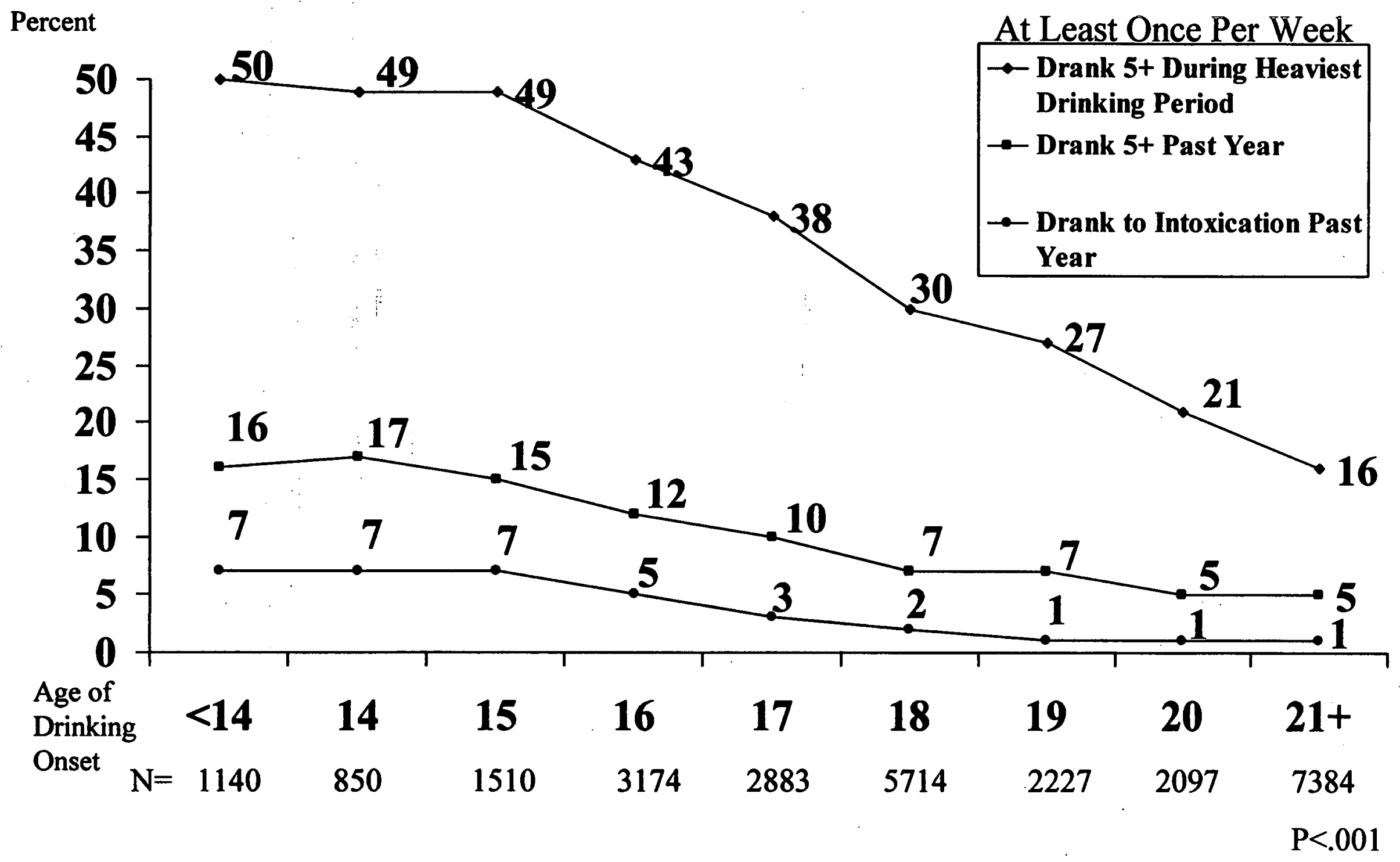




\section{Figure 2. Been in a Situation While or After Drinking that Increased Chances of Injury}

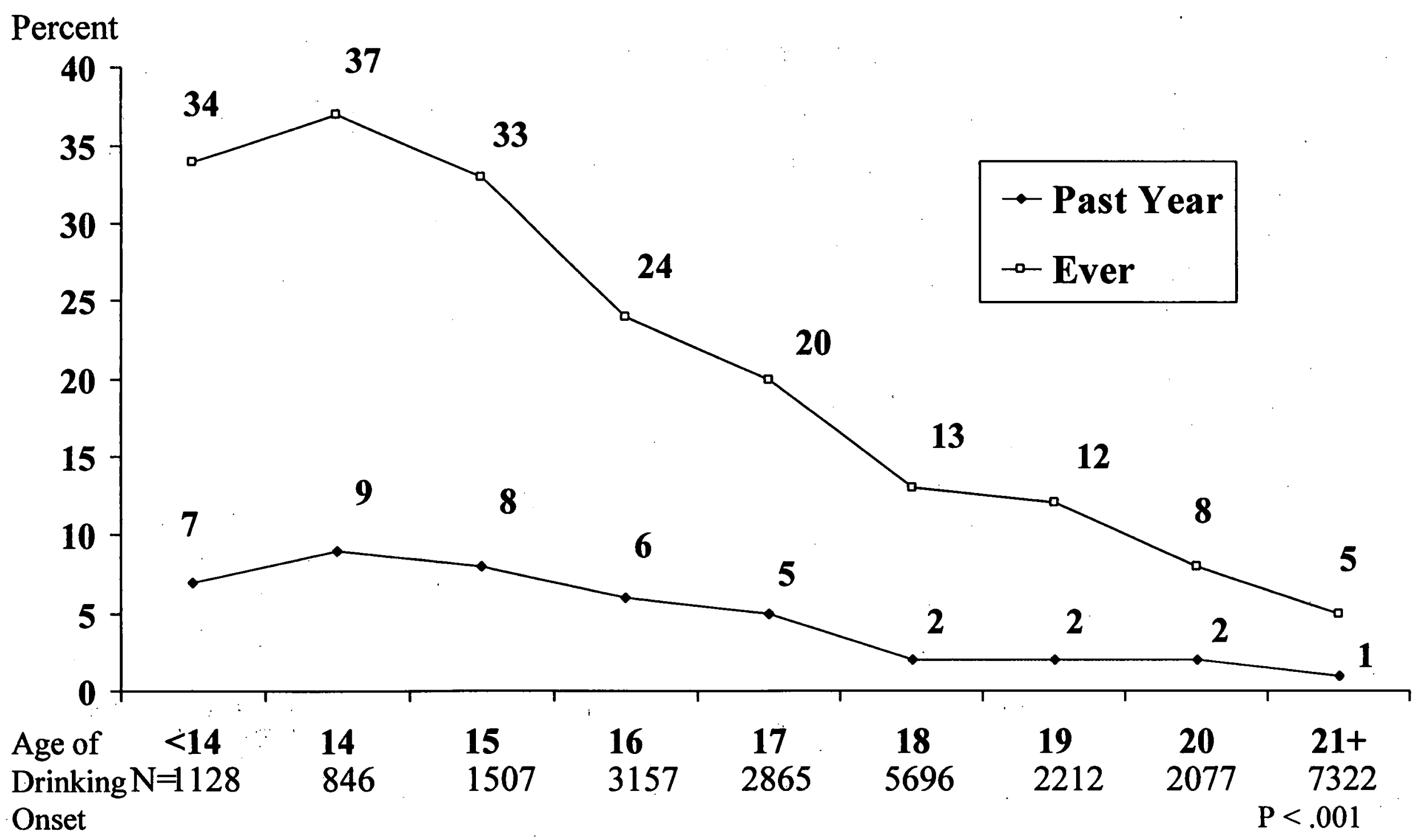




\section{Figure 3. Injured Under the Influence of Alcohol According to Age of Drinking Onset}

Percent

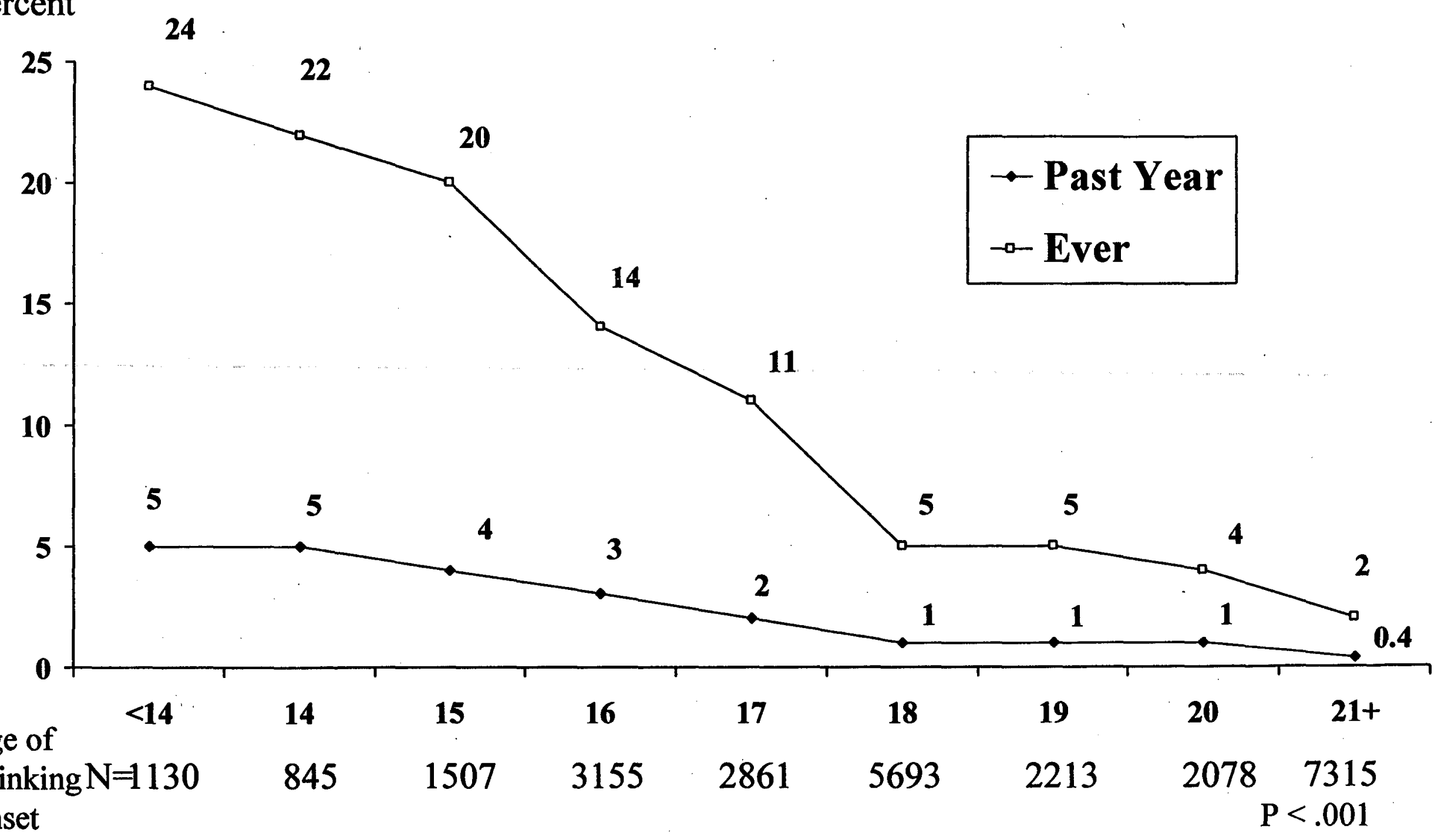


U.S. Department of Transportation

Nationel Mighurey

Treffic Sefely

三三르를

Administretion

Paopla saudng Paoplo

inmmittaciotor

DOT HS 809189

January 2001 